\title{
ARTHUR DANTO E O PROBLEMA DA INTERPRETAÇÃO DE OBRAS DE ARTE
}

\author{
Debora Pazetto Ferreira* \\ deborapazetto@gmail.com
}

RESUMO A definição de arte desenvolvida por Arthur Danto pressupõe que algo é uma obra de arte por ser o correlato de uma interpretação, inscrita em uma rede de significações históricas, teóricas e sociais, que lhe atribui o estatuto de obra de arte. Trata-se de uma definição essencialista que, no entanto, não se funda em algo que é percebido no objeto, mas no objeto percebido como arte. Levando em consideração que o conceito de "interpretação" é um dos pontos cardinais da definição de arte de Danto, aprofundo neste artigo uma investigação específica sobre o assunto. Argumento que o modo como o autor o desenvolve comporta uma ambiguidade, isto é, que há uma confusão entre dois sentidos de interpretação nos textos dantianos, e que seu papel fundamental na definição de arte é inseparável da contextualização histórico-social possibilitada pelo mundo da arte.

Palavras-chave Interpretação, arte contemporânea, Arthur Danto, mundo da arte, critica de arte.

ABSTRACT Arthur Danto's definition of art claims that something is a work of art because it is the subject of an interpretation that is inscribed in a network of historical, theoretical and social meanings, which is responsible for assigning the status of artwork. It is an essentialist definition which however, is not based on something that is perceived in the object, but on the object being perceived as art. In this paper, I develop a specific investigation about the concept of "interpretation", taking into account that it is one of the cardinal points in 
Danto's definition of art. I argue that the author develops this subject in an ambiguous way, in other words, that there is confusion between two different meanings of interpretation in his texts, and that its fundamental role in the definition of art is inseparable from the historical and social contextualization guaranteed by the artworld.

Keywords Interpretation, contemporary art, Arthur Danto, artworld, art criticism.

A partir do século XX, o conceito de arte tornou-se progressivamente relativo e problemático, na medida em que os materiais tradicionais, a representação mimética da realidade e a beleza deixaram de funcionar como indicadores para o reconhecimento de obras de arte. Assim, os aspectos sensoriais que sempre orientaram definições ou teorias sobre a arte tornaram-se cada vez mais sutis ou até mesmo nulos. Os artistas abandonaram a beleza, as molduras, os pedestais, os palcos, a imitação, a materialidade, a habilidade técnica, o predomínio dos sentidos, a individualidade autoral, a permanência dos objetos e, ainda assim, continuaram produzindo obras de arte. Fizeram arte urbana, abstrata, efêmera, artivismo, arte virtual, digital, fizeram arte sobre seus próprios corpos, na terra, nos desertos, usaram animais, rituais, a ciência e o acaso. Esvaziaram galerias, misturaram gêneros, empacotaram museus, foram às ruas e de volta aos cubos brancos, e, ainda assim, tornando obsoletas as definições filosóficas, continuaram produzindo obras de arte.

O filósofo estadunidense Arthur Danto, que vivenciou de perto essas mutações da arte no século XX, enfrentou de uma nova maneira a questão: é possível encontrar uma definição para a arte que se sustente perante a arte contemporânea? O autor desenvolve uma ontologia da arte que, embora implique uma identidade artística fixa e universal (Danto, 2006a, p. 213), pretende abranger tudo o que for compreendido como arte em qualquer tempo e lugar (ibidem, p. 106). Suas teorias sustentam uma definição que permite distinguir a arte do que não é arte, além de ferramentas conceituais para pensar a arte contemporânea em sua singularidade. $\mathrm{O}$ aspecto distintivo da ontologia da arte dantiana é a ideia de que o que faz algo ser uma obra de arte é ser interpretado como tal, sendo essa interpretação, constitutiva de sua identidade artística, historicamente possibilitada pelas narrativas do "mundo da arte". Esse famoso conceito pode ser compreendido como o contexto histórico, social, teórico, 
cotidiano e institucional no qual certas coisas são tratadas como obras de arte: "ver qualquer coisa como arte requer uma coisa que o olho não pode discernir (descry) - uma atmosfera de teoria artística, um conhecimento da história da arte: um mundo da arte" (Danto, 2006b, p. 20).

Em linhas gerais, a definição de arte, que Danto elabora em "A transfiguração do lugar-comum" (2010), pode ser resumida do seguinte modo: a) obras de arte diferem de coisas reais porque são representações; b) isso implica que são sempre sobre alguma coisa, ou seja, têm significado, conteúdo semântico (aboutness); c) o significado é incorporado na parte material da obra, isto é, ele é combinado com seu "modo de apresentação" material; d) há sempre uma dimensão retórica, metafórica e estilística nas obras de arte, situadas na relação entre o significado e seu modo de apresentação; e) obras de arte exigem uma interpretação historicamente contextualizada, que é constitutiva da sua identidade artística. De acordo com o autor, essa definição oferece uma lista de condições necessárias e suficientes para que algo seja considerado e reconhecido como arte. Embora Danto não postule o pertencimento ao "mundo da arte" entre essas condições, parto da hipótese de que esse conceito, elaborado em seu primeiro texto sobre o assunto, é tacitamente pressuposto ao longo de toda a "Transfiguração" e é imprescindível para que sua definição seja bemsucedida. Assim, acrescento uma condição necessária e suficiente à lista acima: f) a interpretação de algo como obra de arte é historicamente possibilitada pelo mundo da arte.

Note-se que, não obstante Danto se considere um essencialista, sua definição não utiliza características sensoriais dos objetos. Algo é uma obra de arte por ser o correlato lógico de uma interpretação, inscrita em uma rede de significações históricas, teóricas e sociais, que lhe atribui o estatuto de obra de arte. "Na verdade, é por ser apresentado dentro de um mundo da arte que um objeto qualquer pode ganhar o estatuto de arte" (Ramme, 2009, p. 207), ou seja, trata-se de uma definição que não se funda em algo que é percebido no objeto, mas no objeto percebido como arte. Fica evidente, portanto, que o conceito de "interpretação" é um dos pontos cardinais da definição de arte de Danto. Levando em consideração sua relevância, aprofundo neste artigo uma investigação específica sobre o conceito de interpretação. Pretendo mostrar que o modo como o autor o desenvolve comporta uma ambiguidade e que seu papel fundamental na definição de arte é inseparável da contextualização históricosocial possibilitada pelo mundo da arte. 


\section{Dois sentidos de interpretação}

Danto introduz o problema da interpretação de obras de arte na "Transfiguração do lugar-comum" propondo, como de costume, um experimento mental: imaginar duas obras de arte que sejam sensorialmente indiscerníveis, mas que foram produzidas em épocas e lugares diferentes. Esse experimento tem o objetivo de mostrar que, embora os objetos materiais que as corporificam sejam idênticos, as referidas obras são distintas, uma vez que têm significados (aboutness) diferentes. Danto concorda, portanto, com a tese wölffliniana de que nem tudo é possível em qualquer época, ou seja, os significados artísticos são condicionados pelo seu contexto histórico (Danto, 2010, p. 174). Desse modo, o problema da interpretação está inserido no cerne da definição de arte, ${ }^{1}$ isto é, na análise do nexo entre o significado de cada obra e o objeto que a constitui materialmente. Ora, se a interpretação artística estabelece relações entre o aspecto significativo e o aspecto sensorial de obras de arte, é de se esperar que ela aconteça somente depois de ter sido estabelecida uma distinção entre arte e realidade. Afinal, objetos cotidianos não solicitam interpretações do nexo entre seu significado e a materialidade na qual este se apresenta publicamente. Por conseguinte, o conceito de interpretação artística não poderia figurar na definição dantiana de arte - a qual estabelece a diferença ontológica entre arte e realidade -, uma vez que se trata de uma ação que pressupõe que essa diferença esteja previamente estabelecida. O autor admite essa consequência lógica em suas considerações sobre reação estética, ${ }^{2}$ todavia, a noção de interpretação acaba sendo desenvolvida de modo mais complexo: como algo que constitui ontologicamente a obra de arte. É nesse ponto que assinalo uma ambiguidade na argumentação de Danto.

Proponho a seguinte hipótese: há dois sentidos diferentes do conceito de interpretação artística que são utilizados indiscriminadamente nos textos de

1 Em seu último livro, Danto constata que não conseguiu estabelecer propriamente uma definição de arte na "Transfiguração do lugar-comum", mas resume sua tentativa com o conceito de "significados corporificados" (2013, p. 37). Em um artigo intitulado "Embodied Meanings, Isotypes and Aesthetic Ideas", o autor afirma que, posteriormente, tentou acrescentar outras propriedades a estas, por admitir que suas condições eram apenas necessárias (2007, p. 125). Ainda que Danto não desenvolva o conceito de corporificação ao longo da "Transfiguração", ele trabalha o conceito de interpretação de uma maneira que indica que a corporificação é o modo como o artista escolhe representar o significado da obra materialmente. Assim, na medida em que articula os significados com sua corporificação, a interpretação está no cerne de definição dantiana de arte.

2 Em "A Transfiguração do lugar comum" (2010), ao abordar a diferença ontológica entre arte e realidade no terreno da estética, Danto defende que nossas reações estéticas são diferentes diante de dois objetos sensorialmente idênticos quando sabemos que um deles é arte e o outro não é. Assim, embora a estrutura da apreciação artística seja diferente da estrutura da apreciação de coisas banais, as diferenças em reações estéticas não podem ajudar a definir a arte. Duas décadas depois, em "O abuso da beleza" (2015), livro em que se aproxima das questões estéticas, o autor mantém a tese de que reações estéticas não fazem parte da definição de arte, justamente porque pressupõem uma distinção prévia entre o que é arte e o que não é. 
Danto. $\mathrm{O}$ autor transita entre esses dois sentidos de modo confuso, sem esclarecer a diferença entre eles. O primeiro sentido refere-se ao ato de interpretar o significado de uma obra de arte em particular: "interpretar uma obra é propor uma teoria sobre o assunto de que ela trata, sobre seu objeto" (Danto, 2010, p. 183). O segundo sentido refere-se ao ato de interpretar algo como arte: "o fundamento lógico em virtude do qual uma mera coisa é elevada ao Reino da Arte consiste naquilo que mencionei de passagem como o ato de identificação artística" (Ibidem, p. 191). ${ }^{3}$ Em ambos os sentidos, a interpretação envolve uma operação de identificação, no entanto, é preciso admitir que o peso ontológico é muito diferente nos dois casos. Passarei a analisar os dois sentidos do conceito de interpretação artística separadamente para, em seguida, avaliar as implicações filosóficas dessa ambiguidade.

\section{Interpretação enquanto ato de identificação artística}

O primeiro sentido de interpretação artística utilizado por Danto refere-se à compreensão do significado de determinada obra de arte. O autor oferece várias indicações de como fazer esse tipo de interpretação. O título, por exemplo, funciona como uma excelente diretriz, mesmo quando a obra é caracterizada como Sem Título, o que acontece com grande parte das pinturas e esculturas modernas e contemporâneas: escolher não intitular uma obra já indica certa concepção sobre a arte (Danto, 2010, p. 183). Ademais, levando em consideração que as obras são intituladas por seus autores, essa indicação aparece como um primeiro sinal do papel fundamental que a intenção do artista adquire nessa concepção dantiana de interpretação.

No experimento imaginário supramencionado, as duas obras perceptivelmente indiscerníveis que são, todavia, produzidas em épocas distintas, são profundamente diferentes porque são constituídas por meio de uma série de identificações de seus elementos, justificada por uma interpretação do sentido da obra. Nesse momento, Danto está trabalhando com identificações de elementos intrínsecos a uma pintura, por exemplo, como a identificação de certa mancha de tinta como Ícaro ou de certa linha como o horizonte. O argumento central aqui é que toda obra de arte é experimentada por alguma interpretação que a estrutura, mesmo que esta não seja expressa linguisticamente: "a estrutura da obra, o sistema de identificações artísticas, se transforma conforme haja diferenças

3 "Primeiro" e "segundo" não se remetem, nesse contexto, a algum tipo de prioridade filosófica entre os dois sentidos de interpretação, tampouco a alguma ordem cronológica relativa aos textos de Danto. Trata-se, simplesmente, da ordem em que os analiso neste artigo. 
de interpretação" (Danto, 2010, p. 184). Ou seja, a obra é configurada por um conjunto de identificações artísticas pertinentes e, embora seja possível haver diferentes estruturações, não existe a possibilidade de não haver nenhuma.

Nos atos de interpretação artística, há uma lógica peculiar da linguagem evidenciada, sobretudo, no uso do verbo "ser". Quando olhamos para uma natureza-morta e afirmamos que certa mancha de tinta "é" uma maçã ou quando afirmamos, no teatro, que certo ator "é" Lancelot, estamos usando o verbo "ser" em um sentido muito específico, diferente de afirmações de identidade reais (quando dizemos que "o céu é o panorama obtido a partir da Terra"), de predicações (quando dizemos que "o céu é azul"), de afirmações da existência (quando dizemos que "o céu é") ou de qualquer uso filosófico (quando dizemos que "o ser é e o não-ser não é"). Em "O mundo da arte", Danto exemplifica esse uso do verbo "ser" com a capacidade tipicamente infantil de "fazer de conta" (2006b, p. 18). Com efeito, quando uma criança afirma, apontando para a boneca, que ela é sua filha, não está afirmando que ela é de fato sua filha, que tem a propriedade de ser sua filha, que substitui sua filha ou qualquer coisa desse tipo. Sua afirmação é perfeitamente compatível com a consciência de que a boneca não é sua filha de verdade. Mais ainda, esse uso específico do verbo "ser" pressupõe que a criança saiba que a boneca não é sua filha no "mundo real" - e essa é a graça da brincadeira -, assim como, na lógica da linguagem que descreve obras de arte, é necessário saber que a mancha de tinta não é uma maçã de verdade. Naturalmente, ninguém expressou essa tese com mais perspicácia do que Magritte.

O "é" usado nesse tipo de interpretação, que Danto chama de "é da identificação artística" (2006b, p. 18), aparenta-se com o "é” usado na magia, na mitologia, na religião e nas metáforas, pois em todos esses casos trata-se de um "é" que transfigura algo. Pelo ato interpretativo, a tinta transfigura-se em paisagens e cenas, o barro transfigura-se em corpos, pessoas em personagens, $o$ espaço bidimensional em espaço tridimensional. Entretanto, essa operação não é tão simples. Ainda que se possa afirmar que cada interpretação estrutura uma obra de arte diferente, mesmo que a coisa física na qual elas se corporificam seja idêntica - como no caso do experimento mental proposto anteriormente-, disso não se segue que é possível estruturar obras de arte de qualquer maneira. Há parâmetros e limites para identificações e interpretações artísticas. Danto é o que poderíamos chamar de "antirrelativista" em relação à interpretação artística: ele defende que as interpretações são verdadeiras ou falsas, que são descobertas e não inventadas, muito embora o ponto de vista oposto seja mais comum a partir da modernidade, isto é, que não há interpretações corretas ou incorretas em arte. Há autores ainda mais relutantes à interpretação, como Susan 
Sontag, por exemplo: "na maioria das instâncias modernas, a interpretação corresponde à recusa filistina de deixar a arte em paz. A arte verdadeira tem a capacidade de nos deixar nervosos. Ao reduzir a obra de arte ao seu conteúdo e interpretá-lo, doma-se a obra de arte" (1966, p. 8). Sontag enfatiza que as interpretações transformam a arte em um artigo de uso teórico, arranjando-a em categorias mentais pré-definidas e, mais do que isso, que elas podem tornar-se procedimentos para controlar e retirar a potência da arte. Essas observações são pertinentes para certo tipo de interpretação, que difere do modo como Danto compreende esse conceito: ele não trata a interpretação como algo externo à obra, que seria acrescentado a ela posteriormente por críticos ou especialistas, mas como algo que a constitui materialmente. Por esse motivo, análises como as de Sontag, que condenam os atos interpretativos por tornarem a arte manejável ou submissa, não fazem sentido em sua teoria. ${ }^{4}$

Danto discorda das concepções que acusam a interpretação de ser uma espécie de véu impedindo a obra de arte de afetar por conta própria - uma variação do retorno fenomenológico à coisa em si -, bem como de todo relativismo que legitima que, assim como cada pessoa tem seu gosto, pode ter sua própria interpretação de obras de arte, ou que interpretações são como espelhos que mostram mais a respeito do interpretador do que da coisa interpretada (Danto, 2014, p. 79). É evidente que todas as pessoas podem construir suas próprias reflexões sobre obras de arte, mesmo que não sejam bem fundamentadas, quando o seu objetivo é ter experiências e sentimentos individuais ou usar as obras como espelhos para enxergar a si próprios. Do mesmo modo, todos podem passear por um museu como quem passeia por um jardim, deixando-se atrair por esta ou aquela imagem como quem colhe flores, sem deter-se em explicações sobre botânica ou sobre o significado da paisagem. Muitas pessoas frequentam museus, teatros e galerias com esse estado de espírito, sem ler os textos explicativos oferecidos e sem buscar qualquer tipo de informação histórica ou processual, e não há nenhum problema nisso. Todavia, quando o objetivo é realmente compreender o significado de uma obra de arte, é preciso interpretá-la, e isso, de acordo com Danto, não pode ser feito de modo relativista.

4 A rejeição da interpretação, em Susan Sontag (1966), baseia-se na premissa de que o Ocidente separou, na arte, a forma do conteúdo e supervalorizou o segundo. Assim, a interpretação é definida como busca teórica e posterior do conteúdo da obra. A autora refere-se, em sua crítica, principalmente a interpretações na literatura, como as análises bíblicas ou as análises freudianas de poesias, que esvaziam os aspectos estéticos e formais das obras em busca de significados "ocultos". Danto, contudo, entende a interpretação de uma maneira bem diferente, isto é, como busca do nexo entre o significado de cada obra e o objeto que a constitui materialmente, logo, como algo que permite inclusive a percepção de seus aspectos estéticos e formais. 
Os limites e parâmetros para as interpretações artísticas, que caracterizam o antirrelativismo dantiano, em muitos casos, são bastante modestos. Por exemplo, quando vemos no palco um cavalheiro em trajes elisabetanos segurando uma caveira, não podemos identificá-lo como Lancelot. Quando vemos um mosaico bizantino, embora possamos pensar sobre a planalidade da superfície como negação do volume ilusório, essa reflexão não será uma interpretação artística do mosaico, pois recorre a teorias que não estavam disponíveis no período de sua fabricação. Esses exemplos mostram que a interpretação, nesse sentido, não é uma camada acrescentada posteriormente às obras de arte, mas o conjunto de elementos materiais e semânticos que se entrelaçam para possibilitar sua produção. Desse modo, a interpretação não pode diminuir a potência da obra, porque ela a constitui, no momento mesmo em que é criada, e, por conseguinte, remete-se constantemente a quem a criou: "como a interpretação é inseparável da obra, ela é inseparável do artista, se ela é obra do artista" (Danto, 2014, p. 80). Ou seja, uma das principais diretrizes para a interpretação é a intenção dos artistas:

\begin{abstract}
Não se pode aplicar os predicados da imaginação a obras ou autores se não conhecemos suas crenças, isto é, se não sabemos como o mundo lhes parece ser [...] A obra construída a partir de uma interpretação deve ser de tal sorte que o artista que supostamente a criou poderia ter desejado que ela fosse interpretada dessa maneira, de acordo com os conceitos disponíveis a ele e à época em que ele trabalhou [...] os limites do artista são restrições especiais à interpretação de obras de arte (Danto, 2010, p. 195-196. Grifo do autor).
\end{abstract}

O autor mostra-se ciente do quanto é complicado determinar os limites de uma interpretação correta em arte, tema que lhe concerne duplamente, como filósofo e como crítico de arte. A referência às intenções dos artistas certamente é um dos critérios mais eminentes em seus textos sobre o assunto. ${ }^{5}$ No entanto, há

5 Danto distingue entre uma "interpretação de superfície" e uma "interpretação profunda". A primeira é constitutiva das obras de arte, recorre às intenções do autor como autoridade e é distinta, devido a esse recurso, da interpretação hermenêutica ou "profunda". A interpretação profunda não se remete às intenções dos autores porque o nível de explicação ao qual se refere não pode ser ocupado por algo ou alguém em posição de autoridade. Trata-se de um tipo de interpretação frequente nas ciências humanas, principalmente na sociologia e na análise literária (sobretudo nas teorias psicanalíticas, marxistas e estruturalistas), que recorre a explicações e analogias inconscientes, forças sócio-históricas complexas e estruturas linguísticas profundas. Nesses casos, o autor não está em posição privilegiada para falar de sua obra, porque a "profundidade" em questão é inconsciente, logo, funciona como se fosse algo externo ao sujeito. A única autoridade possível é o próprio teórico, o qual, no entanto, não cria as realidades sobre as quais tem autoridade, como é o caso dos autores no contexto da interpretação de superfície. Fica claro, portanto, que as críticas à interpretação artística como algo que não deixa a obra "falar por si mesma", como a de Susan Sontag, incidem sobre o conceito de interpretação profunda. Esse tipo de interpretação pode ser "invenção crítica", "literatura" ou "hermenêutica", mas não é interpretação artística no sentido dantiano, que é sempre "de superfície": remete à autoridade do autor (Danto, 2014). 
uma proposição e uma precaução implícitas no uso grifado da palavra "poderia": em diversos casos, não temos acesso à intenção do artista, entretanto, há diversos fatores culturais, históricos e sociais que ajudam a delimitar, em linhas gerais, o que poderia ser sua intenção. Mesmo que o artista não ofereça um título, nem indicações a respeito de sua obra, se conhecemos sua localização temporal e geográfica, podemos ter alguma noção de suas experiências e concepções. Em suma, a interpretação está condicionada, no mínimo, pelas possibilidades histórico-culturais da obra interpretada.

Em um texto denominado "Linguagem, Arte, Cultura, Texto", Danto desenvolve esse tema de outra maneira: imagens artísticas são como textos, isto é, devem ser lidas (2014, p. 110). Ler, naturalmente, envolve interpretar o significado dos símbolos gráficos, e não apenas percebê-los como borrões de tinta ou relevos sobre o papel. Do mesmo modo, a materialidade que constitui a obra de arte precisa ser "lida", o que deve ser feito levando-se em consideração o contexto cultural no qual ela foi produzida. Por exemplo, precisamos conhecer a sociedade inglesa do século XVIII - com sua moralidade burguesa e protestante, bem como o conjunto de valores e vícios que protagonizavam um verdadeiro drama moral moderno - para compreendermos o sentido ético, satírico e pedagogicamente narrativo das gravuras de William Hogarth. Danto defende, distorcendo ligeiramente o mote fregiano de que uma palavra adquire significado apenas no contexto de uma sentença, que o significado das obras de arte pode ser procurado apenas no contexto (Zusammenhang) cultural no qual elas surgem. É evidente, no entanto, que a estrutura de uma obra de arte não se iguala à estrutura de uma sentença, e as habilidades críticas para interpretá-la não se assemelham às competências gramaticais, sintáticas e semânticas para compreender uma frase ou estabelecer seu valor de verdade. Por esse motivo, Danto utiliza o conceito "texto" no terreno da arte, em vez de "linguagem" ou "sentença", aproximando-se da tradição continental e afastando-se da Filosofia da linguagem analítica (2014, p. 112-113). “Texto" é um termo mais abrangente, uma vez que pode ser pictórico ou verbal e adapta-se à arte justamente porque ultrapassa a análise lógica, gramatical, pictural e sintática - exige uma análise mais ampla, interpretativa, que se remete ao contexto cultural no qual suas conexões de sentido, suas referências e suas alusões são possíveis.Em "Crítica de arte após o fim da arte", Danto descreve sua atividade de crítico de arte como uma posição intermediária entre artistas e público, adotando uma atitude quase pedagógica: "eu vejo minha tarefa como mediação entre o artista e o espectador, ajudando os espectadores a apreender o que foi intencionado" (2013, p. 16). Com efeito, as interpretações dos críticos - cada vez mais requisitadas na arte contemporânea - podem envolver diversas teorias da arte, observações 
contextuais sobre o mundo da arte, detalhes históricos e biográficos, entre outros, como as interpretações que Danto elabora sobre as pinturas de pincelada de Lichtenstein ou sobre a composição cromática do teto da Capela Sistina. Também podem referir-se a situações despretensiosas, como revelar quais partes do objeto material fazem parte da obra: é preciso recorrer às intenções do artista para saber se estamos diante de uma escultura de um gato acorrentado ou diante de uma escultura de um gato, que foi acorrentada para evitar o roubo; é preciso pesquisar as intenções de Duchamp para saber se a posição da ampola de vidro faz parte de "Ar de Paris", isto é, se estar pendurado no teto pertence ao significado da obra ou se foi uma escolha curatorial.

Dúvidas sobre a identificação dos componentes que pertencem às obras são cada vez mais recorrentes em exposições de artes visuais, nas quais, muitas vezes, os curadores inserem elementos e organizam os trabalhos de modo bastante original. Na "Documenta de Kassel", de 2012, por exemplo, a diretora artística, Carolyn Christov-Bakargiev, organizou um espaço central na rotunda do museu Fridericianum onde compilou diversos objetos, entre os quais havia obras de arte e coisas banais. O próprio estatuto desse "aquário", que Bakargiev denominou "The Brain", é ambíguo, pois é difícil decidir se ele é uma exposição de arte ou uma obra de arte. Dentro dele, havia algumas pinturas de Morandi e, à frente delas, alguns dos objetos que aparecem em suas pinturas - garrafas longilíneas, potes de cerâmica, caixas -, os quais, em sua presença sólida, fora das telas, proporcionavam uma experiência realmente nova. Alguém que não conhecesse Morandi poderia acreditar que sua obra consistia na dupla apresentação dos utensílios, enquanto coisas e enquanto pinturas, condenadas a se defrontar em uma especularidade muda. Assim, a obra poderia ser interpretada como uma reflexão sobre a perda da individualidade entre o que reflete e o que é refletido, ou então como uma provocação à tese platônica de que a pintura imita os objetos. Essas interpretações podem ser interessantes, mas são incorretas, porque se baseiam em uma falsa identificação artística, que toma os objetos como parte da obra de Morandi. O fato de haver interpretações incorretas, nesse sentido, demonstra que elas não são completamente relativas. Para interpretar adequadamente a obra de Morandi, constituída apenas pelas pinturas, é preciso recorrer a informações sobre o artista, e, para interpretar a instalação em "The Brain", é preciso recorrer a informações sobre o projeto curatorial de Bakargiev. Pode-se discutir se essa curadoria desvirtua a obra ou cria uma nova obra de arte apropriando-se de uma já existente, como nos "Triptychos Post Historicus" de Braco Dimitrijevic. O ponto, todavia, é que justamente quando há todas essas possibilidades de obras, apropriações, montagens e camadas a identificação artística e a interpretação - compreendidas de modo não relativista - mostram sua 
relevância. Entender as obras e distingui-las é possível porque "há uma verdade na interpretação e uma estabilidade nas obras de arte que não são de modo algum relativas" (Danto, 2014, p. 80).

\section{Interpretação enquanto ato de identificação ontológica da arte}

Na seção anterior, descrevi um sentido do termo "interpretação" utilizado por Danto, isso é, enquanto identificação de elementos pertinentes dentro de uma obra de arte, com base em certa "leitura" sobre seu significado, que é, por sua vez, fundada em uma compreensão mais abrangente da cultura, da época e das possíveis intenções do artista que a produziu. Há, todavia, outro sentido de "interpretação" nos textos de Danto, o qual, como afirmei anteriormente, tem mais peso ontológico. O conceito de interpretação, nesse segundo sentido, pode ser detectado em várias passagens de "A transfiguração do lugar-comum" como "o fundamento lógico em virtude do qual uma mera coisa é elevada ao Reino da Arte consiste naquilo que mencionei de passagem como o ato de identificação artística" (2010, p. 191), ou "dado o caráter constitutivo da interpretação, o objeto não era obra antes de ser interpretado" (2010, p. 190). Em "O mundo da arte", há afirmações que operam com o mesmo sentido de interpretação: "é uma condição necessária para algo ser uma obra de arte que alguma parte ou propriedade dele seja designada pelo sujeito de uma sentença que emprega esse é especial" (2006b, p.18), no caso, o "é" da interpretação artística. Também em "O descredenciamento filosófico da arte" há afirmações semelhantes: "a interpretação é a agência do que eu chamei de transfiguração, esse processo por meio do qual mesmo objetos totalmente do lugar-comum são alçados ao nível da arte" (2014, p. 114).

Meu argumento é o seguinte: é necessário diferenciar claramente, o que Danto não faz, entre interpretação no sentido de identificar que as manchas coloridas na pintura são maçãs - ou interpretar que as maçãs pintadas por Cézanne significam sua compreensão da pintura como recriação do volume encarnado dos objetos, ou, ainda, identificar que certa donzela esculpida em mármore é Flora e certo rapaz no palco é o filho de Napoleão - e interpretação no sentido de interpretar certo objeto ou ação como arte. Em ambos os casos, a interpretação envolve uma operação de identificação e transfiguração. Entretanto, no primeiro caso, transfigura-se um elemento que já pertence a algo que é compreendido como obra de arte, ao passo que, no segundo, transfigura-se algo em arte. É nesse segundo caso que podemos detectar propriamente a famosa transfiguração do lugar-comum, isto é, a transformação de uma coisa banal em arte. No primeiro caso, a coisa interpretada já é percebida como 
arte, no segundo, a interpretação precisa efetuar uma transição categorial, na qual um objeto ou ação deixa de pertencer à categoria ontológica das coisas comuns e passa a pertencer à categoria ontológica da arte. Proponho chamar esse processo de "ato de identificação ontológica da arte", para diferenciar do "ato de identificação artística" nomeado por Danto.

No ato de identificação ontológica da arte, identifica-se algo como arte, logo, como passível de um ato de identificação artística. Ou seja, interpretase a coisa como coisa a ser interpretada artisticamente. Após esse ato de categorização ontológica, a coisa passa a pertencer ao "reino da arte". Esse é o papel fundamental da interpretação na definição de arte: como ato de identificação ontológica, a interpretação é uma condição necessária para que algo seja considerado e reconhecido como arte (Danto, 2010, p. 190). Ou seja, perceber algo sem saber que é arte é o mesmo que perceber a mera coisa material: "na qualidade de um processo de transformação, a interpretação é algo como um batismo, não por dar um nome ao objeto, mas por emprestar-lhe uma nova identidade e fazê-lo ingressar na comunidade dos eleitos" (Ibidem, p. 190, 191), isto é, o objeto só é transfigurado em arte ao ser interpretado como tal, passando do mundo do banal para o mundo dos "eleitos", das coisas que adquiriram significado artístico.

Há uma breve passagem em "O descredenciamento filosófico da arte" na qual Danto faz uma observação que explicita a diferença entre os dois sentidos de interpretação, embora ele não desenvolva o assunto. O autor afirma que podem ocorrer dois erros na interpretação de obras de arte, a saber, interpretar como arte algo que não é arte e interpretar uma obra de arte de modo incorreto (2014, p. 75-76). Ora, o primeiro é um erro no nível do que chamei de identificação ontológica da arte, e o segundo no nível das identificações artísticas em obras de arte. Ainda que Danto mencione essas duas possibilidades de erro, ele parece não perceber que cada erro procede de um sentido ou nível ontológico diferente do conceito de interpretação. Não atentar para essa diferença tem ao menos uma consequência filosófica grave: o autor acaba discorrendo vastamente, em diversos textos, sobre a identificação de elementos em obras de arte, sobre a relação entre o significado e seu modo de apresentação em uma obra ou sobre como isso se relaciona com a prática crítica, contudo, ele não aprofunda a questão da interpretação como transição da categoria das coisas banais para a categoria da arte. Ou melhor, ele afirma, no contexto da sua definição de arte, que essa transição acontece por meio interpretação (no sentido da identificação ontológica da arte), mas, ao desenvolver o tema, simplesmente oferece inúmeros exemplos e explicações sobre a interpretação de elementos e significados dentro de obras de arte (no sentido da identificação artística). Desse modo, Danto 
esquiva-se de explicar como a interpretação efetua a transfiguração do lugarcomum, isto é, por meio de quais critérios de reconhecimento ou legitimação a interpretação transforma algo banal em arte - sendo que esse é seu grande problema filosófico.

Em um trecho de "A transfiguração do lugar-comum", Danto imagina um "homem comum", equivalente ao Sr. Testadura de "O mundo da arte", o qual, diante de uma pintura abstrata, afirma que vê apenas tinta e pano. A mesma declaração poderia ser feita por um artista "olfativo" engajado na questão do retorno da arte à materialidade simples da realidade. Em ambos os casos, a frase "isto é apenas tinta e nada mais" poderia ser proferida, entretanto, com significados muito diferentes: a frase do artista representa uma interpretação sobre a arte e a do homem comum representa a falta de interpretações artísticas sobre um objeto material. São frases indiscerníveis, contudo, representam afirmações diferentes, uma vez que a do artista "se deu em meio a uma atmosfera impregnada de teorias da arte e de história da arte (que ele conhece), e que nesse movimento ele rejeitava de uma forma artística toda uma classe de posicionamentos em face de objetos de arte" (Danto, 2010, p. 200-201). O famoso problema dos indiscerníveis aparece aqui em uma nova camada: como diferenciar uma frase que afirma uma interpretação artística de uma frase que lhe é materialmente indiscernível, mas que não comporta a mesma afirmação? De acordo com Danto, isso só é possível em relação à atmosfera histórica e teórica em que as sentenças são proferidas. Ou seja, o que permite identificar uma interpretação artística como interpretação artística é essa atmosfera, isto é, o mundo da arte.

$\mathrm{O}$ artista acima regressou às mesmas sentenças do homem comum, mas, ao modo de um mestre budista, "voltou a elas depois de percorrer o caminho de um complexo conjunto de exercícios espirituais e de uma metafísica e uma epistemologia notáveis" (Danto, 2010, p. 201) - essa citação, ironicamente, é ela própria indiscernível de alguma frase que descreva o percurso histórico do Espírito em Hegel. Não por acaso, a teoria de Danto fundamenta-se, com uma tônica bastante hegeliana, no percurso histórico da arte. É pela grande trajetória narrativa da história da arte que podemos chegar a essa atmosfera altamente teórica, o mundo da arte contemporânea, que permite interpretar como arte algo idêntico a uma coisa banal - uma caixa de esponjas de aço, uma roda de bicicleta, uma lata de sopa de tomates - e estabelecer uma diferença de categorias ontológicas entre elas. A mesma atmosfera permite, paralelamente, identificar como interpretação artística uma frase indiscernível de outra que não é uma interpretação artística. Fica evidente, portanto, que o conceito de interpretação, tanto no sentido do ato de identificação ontológica da arte quanto 
no sentido do ato de identificação artística, é inseparável da contextualização histórico-social possibilitada pelo mundo da arte.

\section{Considerações finais}

O conceito de interpretação é fundamental na filosofia de Danto, na medida em que opera como uma condição necessária em sua definição de arte: algo é uma obra de arte por ser objeto de uma interpretação que lhe atribui esse estatuto. Todavia, trata-se de um conceito que permanece obscuro, na medida em que o autor o utiliza ambiguamente, ora no sentido de interpretar elementos no contexto prévio das obras de arte - a relação entre os significados e a materialidade das obras, com base no que poderia ser a intenção de seus autores -, ora no sentido de interpretar ontologicamente coisas banais como arte. Além disso, o autor não explica claramente como essa transição categorial é possível e como ela é indissociável das teorias e instituições do mundo da arte.

O que estou afirmando é o seguinte: se Danto afirma que a interpretação é uma condição essencial da arte, deveria ao menos perguntar-se como, por meio de quais procedimentos, ela opera essa elevação das coisas comuns ao "reino da arte". Por exemplo, basta que alguém acorde com humor duchampiano e interprete sua cafeteira como arte para que ela seja transfigurada em obra de arte? Ou é preciso que uma comunidade reconheça publicamente a interpretação de algo como arte para que essa interpretação seja realmente transfiguradora? $\mathrm{Ou}$, ainda, é preciso que algo esteja em uma galeria, teatro, universidade ou museu para ser arte? Essas perguntas se enovelam em torno da relação mal explicada - ou mal assumida - entre interpretação e mundo da arte. Danto não deixa claro se é necessário que o objeto seja apresentado no mundo da arte para que se possa interpretá-lo como arte, ou se ele só pode ser apresentado no mundo da arte porque já foi interpretado como arte. Na primeira hipótese, seria necessário elucidar como o objeto entra primeiramente no mundo da arte para depois ser interpretado como obra. Seria por decisão de um grupo de especialistas e curadores? Ou porque seu autor tem formação universitária ou currículo de artista? No segundo caso, seria preciso explicar onde, quando e quem tem o poder de interpretar uma coisa banal como arte a ponto de inserila no mundo da arte. Em outras palavras, seria preciso explicar por que certos objetos interpretados em determinadas circunstâncias como arte são elevados ao reino da arte enquanto outros, como a cafeteira supramencionada, não são. Por acaso? Ou porque seria preciso levar a cafeteira - é claro, previamente interpretada como arte - até uma galeria respeitável e convencer um grupo de críticos e curadores de que se trata de uma obra de arte legítima? Ou então 
porque a pessoa que interpretou a cafeteira como arte é um artista conhecido e, portanto, tem um poder especial parecido com o do rei Midas de transfigurar coisas ordinárias em arte?

É evidente que essas perguntas não podem ser respondidas sem uma investigação empírica sobre as relações pessoais, acadêmicas, teóricas, institucionais, regionais, raciais, políticas e mercadológicas que configuram o mundo da arte. Provavelmente, é por esse motivo que Danto esquiva-se delas - são perguntas que explicitam que os fantasmas do institucionalismo e da contingência continuam rondando sua definição essencialista de arte. Essa esquiva aparece no formato de uma confusão entre os dois sentidos de interpretação que aparecem nos textos de Danto. A interpretação é uma condição essencial da arte como ato de identificação ontológica da arte - "o objeto não era obra antes de ser interpretado" (2010, p. 190) -, logo, seria necessário, para dar consistência à sua definição, responder as perguntas anteriores, isto é, explicar quais são as condições necessárias para que algo banal seja interpretado como arte. $\mathrm{O}$ autor, no entanto, salta por cima dos problemas e aprofunda-se apenas na interpretação artística, ou seja, na identificação de elementos significativos incorporados materialmente em objetos ou ações que já foram interpretados previamente como obras de arte. Assim, permanece obscuro, na definição de arte dantiana, como funciona a complexa relação entre o conceito histórico $e$ contextual de mundo da arte e as condições necessárias e suficientes, isto é, essenciais (fixas e universais), entre elas a interpretação, para que algo seja arte.

\section{Referências}

CARROLL, N. "Essence, Expression, and History: Arthur Danto's Philosophy of Art". In: ROLLINS, M. Danto and his critics. Oxford: Blackwell, 1993.

DANTO, A. C. “A transfiguração do lugar comum”. Tradução de V. Pereira. São Paulo: Cosac Naify, 2010.

. "Após o fim da arte: a arte contemporânea e os limites da História". Tradução de S. Krieger. São Paulo: Odysseus, 2006a.

Jul. 2006b.

"O mundo da arte". Tradução de R. Duarte. Artefilosofia, Nr. 1, pp. 13-25, . "O descredenciamento filosófico da arte". Tradução de R. Duarte. Belo Horizonte: Autêntica, 2014.

. "O abuso da beleza". Tradução de P. Süssekind. São Paulo: Martins Fontes, 2015. . "Crítica de arte após o fim da arte". Tradução de M. Gally, Clarissa B. e L.

Aguiar. Viso: Cadernos de estética aplicada, Vol. VII, Nr. 14, pp. 1-17, Jul./Dez. 2013. . "What Art Is". Yale: Yale University Press, 2013. 
. "Beyond the Brillo Box: the Visual Arts in Post-Historical Perspective. Berkeley". Los Angeles, London: University of California Press, 1992.

."Encounters and Reflections: Art in the Historical Present". New York: Farrar, Straus \& Giroux 1990.

. "Embodied Meanings: Critical Essays \& Aesthetic Meditations". New York:

Farrar, Straus \& Giroux, 1994.

RAMME, N. “É possível definir arte?”. Analytica, Vol. XIII, Nr. 1, pp. 197-212, Jul. 2009. SONTAG, Susan. “Against interpretation”. New York: Farrar, Straus \& Giroux, 1966. 